\title{
A Survey of Symptoms of Fungal Disease in Sugarcane (Saccharum officinarum L.) in Buea, in the South West Region of Cameroon
}

\author{
Eneke Esoeyang Tambe Bechem ${ }^{1^{*}}$ and Clara Elinge Jackai Mbella ${ }^{1}$ \\ ${ }^{1}$ Department of Botany and Plant Physiology, Faculty of Science, University of Buea, P.O.Box 63, \\ Buea, Cameroon.
}

Authors' contributions

This work was carried out in collaboration between the two authors. Both authors read and approved the final manuscript.

Article Information

DOI: $10.9734 / A R R B / 2019 / v 31 i 330047$ Editor(s):

(1) Dr. Msafiri Yusuph Mkonda, Lecturer, Sokoine University of Agriculture, Tanzania. (2) Dr. George Perry, Dean and Professor of Biology, University of Texas at San Antonio, USA

Reviewers:

(1) Dirk Janssen, IFAPA, Centro La Mojonera, Spain. (2) Jackson Venusto Modi Lado, University of Juba, South Sudan Complete Peer review History: http://www.sdiarticle3.com/review-history/47825

Original Research Article

Received 03 January 2019

Accepted 21 March 2019

Published 26 March 2019

ABSTRACT

Aim: Sugarcane (Saccharum officinarum L.) which is mostly cultivated in tropical and subtropical regions of the world is an important source of sucrose. This crop which was originally grown in South Eastern Asia and the Pacific for the sole purpose of chewing is mainly used nowadays for the production of sugar, bio-fuels, medicine etc. In spite of its numerous uses, the production of sugarcane in Buea, South West region of Cameroon is hampered by many factors including the incidence of disease. It is possible that some varieties are no longer cultivated because of their susceptibility to fungal diseases. It was for these reasons that we decided to survey the sugarcane farms in this area, to evaluate the presence of diseased symptoms due to activity of fungi.

Study Design: Random sampling.

Place and Duration of Study: Buea and its environs, Rubber Pathology Laboratory IRAD Ekona, and Life Sciences Laboratory, University of Buea, between June 2016 and July 2017.

Methodology: During the survey, sugarcane farms in five villages in Buea and its environments were visited. The leaves and stems of the plants were observed for any symptoms of fungal activity. The incidence, severity and prevalence of the symptoms were noted. Leaf samples were collected 
from diseased sugarcane plants and transported to the laboratory for the isolation of fungi on Potato Dextrose Agar growth medium. The isolates were identified based on their cultural and micromorphological characteristics.

Results: Sugarcane plants with fungal disease symptoms were seen in all the farms visited during the survey, thus a prevalence of $100 \%$. The disease incidence varied from $54-100 \%$, while the severity ranged from $20-55 \%$. Two genera of fungi were isolated from the diseased plants viz: Chaetomium sp. and Bipolaris sp.

Conclusion: Chaetomium and Bipolaris are associated with fungal symptoms in diseased sugarcanes hence any management plans geared towards the improvement of sugarcane production in this area must include control measures for these fungi.

Keywords: Sugar cane; Chaetomium; Bipolaris; Fungal disease.

\section{INTRODUCTION}

Sugarcane (Saccharum officinarum L.) is an important crop due to its immense uses with its industrial potential. Sugarcane contributes about $70 \%$ of the total world sugar requirements, with the remaining $30 \%$ being accounted for by sugar beets [1]. It is a major industrial cash crop, with a potential in bio-factory evolution, because it produces high yield valuable products like sugar, bio-fibres, waxes, bio-plastic and bio-fuels [2]. The Brazilian experience in sugarcane ethanol production has encouraged the establishment of a consolidated world supply to meet the demand of a proposed ethanol addition of approximately $10 \%$ to gasoline worldwide [3]. The cultivation of sugarcane is widespread in tropical areas, covering a total of approximately 19.4 million hectares as a single crop worldwide [4]. The productivity of sugarcane varies from country to country; Brazil (73 tons/ha), India (64.5tons/ha), China (64 tons/ha), Cuba (22.5tons/ha). In Africa, the highest productivity is observed in South Africa (49.5tons/ha) followed by Egypt (13 tons/ha) [5]. Cameroon ranks 51 in the world amongst the sugarcane producing countries and her production quantities has dropped from $1,450,000$ tons in 2009 to 1.200 .000 tons in 2013. This decrease in production continues with the increase in population and the attendant need for land for the construction of houses and other uses.

The sugar producing company in Cameroon, SOSUCAM (Cameroon Sugar Company) grows 28,000 hectares of sugarcane plantation located in Mbanjock and Nkoteng both of which are situated $100 \mathrm{~km}$ North of Yaoundé in the Centre region. SOSUCAM produces 130,000 tons of sugarcane and 105,000 tons of sugar annually [6]. SOSUCAM cannot meet the demand of the Cameroonian markets for sugar which stands at 200,000 tons per annum. Due to this challenge sugar is still imported into the country to meet the high demand. In this light, in 1998 Cameroon produced 80.000 tons of sugar but consumed 110.000 tons; the surplus was imported at a cost of 8.1 billion CFA [6].

Apart from SOSUCAM in Cameroon, sugarcane is also produced by small holder farmers as food crop. In the South West Region of Cameroon, particularly in Buea and its environs, there are sugarcane farms owned by small holder farmers. The sugarcane produced from these farms is mainly for local consumption (chewing) and is thus sold to traders from Buea and the surrounding cities such as Limbe, Douala, Kumba etc.

Diseases are very prominent among the constraints limiting sugarcane productions worldwide. About a hundred diseases of sugarcane have been reported from different parts of the world [7]. Red rot of sugarcane which is one of the most important fungal diseases in Bangladesh is responsible for about $10-15 \%$ yield reduction [4]. In Cameroon, [8] observed sugarcane orange rust disease at Mbanjock and Nkoteng. However, information on the different fungi associated with diseased sugarcanes in Buea has been scarce. This study was therefore aimed at surveying sugarcane farms in Buea area, to evaluate the presence of diseased symptoms due to activity of fungi.

\section{MATERIALS AND METHODS}

\subsection{Description of Study Site}

This study was carried out in Buea and its surrounding environments, along the slope of Mount Cameroon (Fig. 1), in the South West Region of Cameroon. The area has a humid tropical climate and the climatic pattern is sharply modified by the influence of topography. The 
mean annual rainfall is about $2085 \mathrm{~mm}$. The mean annual temperature at sea level is about $28^{\circ} \mathrm{C}$ and it decreases by $0.6^{\circ} \mathrm{C}$ per $100 \mathrm{~m}$ of ascent to $1^{\circ} \mathrm{C}$ at the summit of the mountain. The Relative humidity is $86 \%$ and sunshine is 900 to $1200 \mathrm{hrs}$ per annum [9].

The Buea area is characterized by semi permanent mist and cloudiness. The landscape of the study area is steeply sloping with rocky ridges conforming to individual lava flows separated by numerous ravines. The soil type is mainly volcanic and relatively fertile. The soils are much deeper, nutrient rich, less stony and therefore intensively cultivated [10].

The forest of this region has been replaced by shifting cultivation or organized commercial plantations, mainly palms, banana and rubber scattered over the region. The vegetation is made up of forest consisting of diverse plant species.

\subsection{Farm Survey}

A survey was carried out in sugar cane growing areas which had previously been identified from a recognizance survey. The villages located in Buea sub - division included Muea, Maumu, Moli, Upper farms and Wolikawo. The farms for the survey were randomly chosen in each village. Each farm considered for the survey had at least ten stools of sugarcane. During the visit to the farms, a visual observation was done on the leaves of all the sugarcane plants and the presence of signs and symptoms of fungal

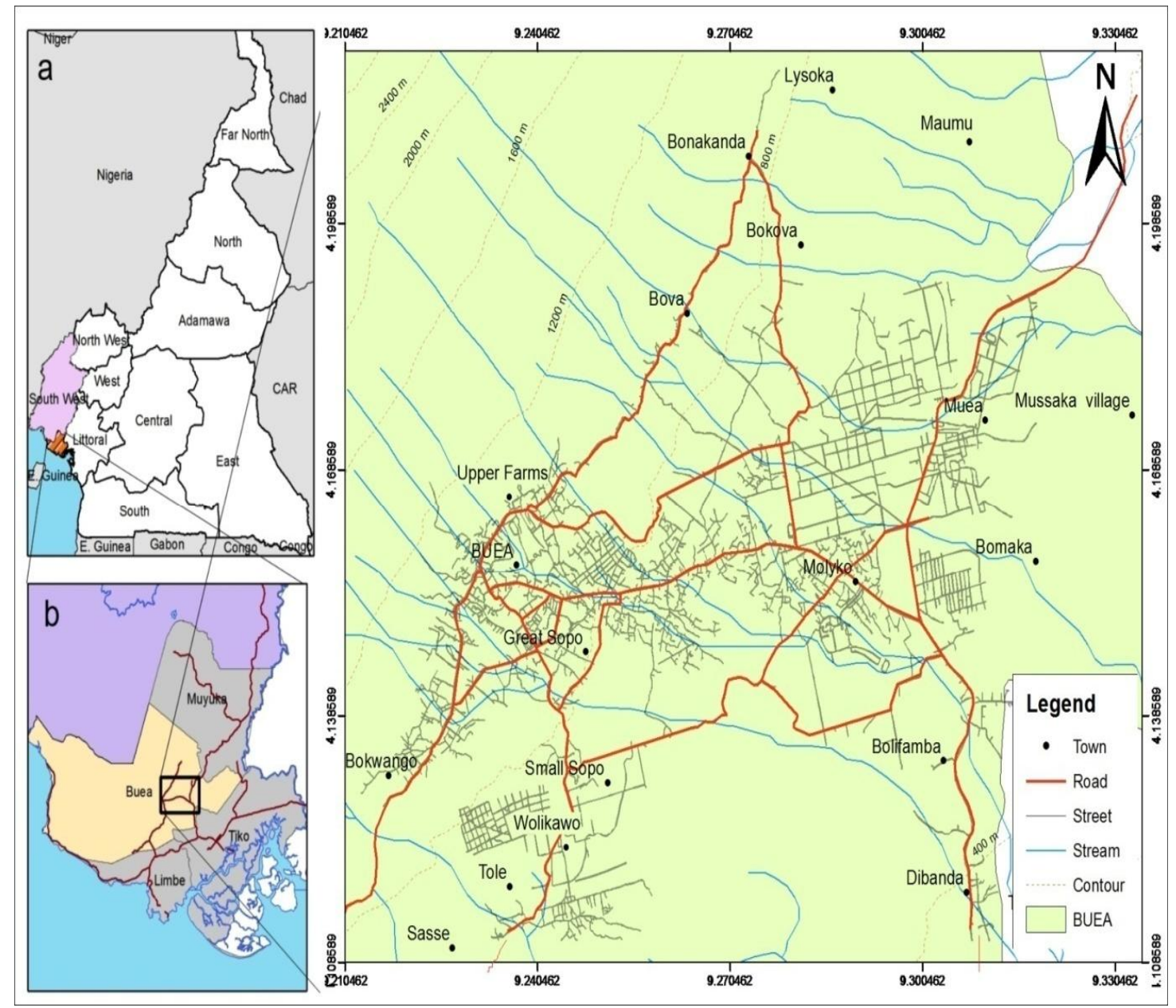

Fig. 1. Location of study area highlighting survey sites

(a: Cameroon locating South West. $b$ :South West locating Fako. $c$ :Buea and its environs showing study sites (Remote Sensing Unit University of Buea) 
infection were recorded. The variety of sugar cane grown in the farm was noted. We also evaluated whether the farms were weeded regularly or not.

Semi - structured questionnaires were administered to farm owners to gather information on their farm size, age of crops, landrace type, agronomic practices, cropping patterns etc.

Leaves of sugarcane plants exhibiting signs and symptoms of fungal infections were collected randomly from each sugarcane farm. The collected samples were placed in paper bags and taken to the Rubber Pathology Laboratory in the Institute of Agronomic Research and Development (IRAD) Ekona, for the isolation of fungi.

\subsubsection{Sampling for disease incidence}

To be able to determine the disease incidence, 3 $x 3 \mathrm{~m}$ quadrats were laid down in each farm. The distance between quadrats was $4 \mathrm{~m}$. The numbers of plants with fungal-like symptoms as well as the total number of plants were recorded per quadrat and per farm.

The disease incidence, which is the number or proportion of plant units that are diseased (the number or proportion of plants, leaves, stems and fruits that showed any symptoms) in relation to the total number of units examined [11] was calculated using the formula in (1).

Incidence $(\mathrm{I})=$ (Number of plants with diseased symptoms / Number of plants observed) $\times 100$

\subsubsection{Sampling for severity}

In each farm 10 sugarcane stools were randomly selected for the evaluation of disease severity. The third leaf from the top visible dewlap on stalks was used to evaluate disease severity. Disease severity which is the measure of the damage done by a disease [11] was assessed using the visual assessment methods following the table developed by Horsfall and Heuberger [12] (Table 1).

The disease severity index was calculated as in (2) [11].

Disease severity Index $=($ Sum of all disease ratings / (Total no. of ratings $x$ max. disease grade)) $\times 100$
Table 1. Disease severity scale developed by Horsfall and Heuberger

\begin{tabular}{ll}
\hline Category & Severity \\
\hline 0 & Apparently infected \\
1 & $0-25 \%$ leaf area infected \\
2 & $26-50 \%$ leaf area infected \\
3 & $51-71 \%$ leaf area infected \\
4 & $>75 \%$ leaf area infected \\
\hline
\end{tabular}

\subsubsection{Disease prevalence}

A total of twenty-five farms were observed for fungal symptoms, in order to determine the disease prevalence. Prevalence was calculated as the number of farms, where a disease or pathogen has been detected, divided by the total number of the farms evaluated [11].

\subsection{Isolation of Fungi from Diseased Leaves}

\subsubsection{Growth medium preparation}

The medium used was Potato Dextrose Agar (PDA) prepared according to the Manufacturer's instruction (Difco). In the preparation process, 42 $\mathrm{g}$ of powdered medium was weighed and put in a conical flask. Distilled water was added to dissolve the powder and the volume was made up to $1000 \mathrm{ml}$. The medium was sterilized by autoclaving at $121^{\circ} \mathrm{C}$ and $15 \mathrm{psi}$ for 15 minutes and allowed to cool. The medium was supplemented with filter-sterilized streptomycin sulphate $30 \mathrm{mg} / \mathrm{l}$. Medium was poured into $9 \mathrm{~mm}$ diameter sterile Petri dishes for use in the isolation of fungi.

\subsubsection{Isolation and identification of fungi}

Fungi were isolated from sugarcane leaves that exhibited symptoms of fungal infection that were collected during the field survey. The protocol employed was that described in [13].

In the isolation process, the infected leaf samples were washed under running tap water to remove surface soil, dust and other contaminants. The leaves were cut into small pieces of about 2$5 \mathrm{~mm}$. The pieces were surface sterilized by dipping in $70 \%$ ethanol for $1 \mathrm{~min}$, followed by soaking in $4 \%$ sodium hypochlorite solution for 2 5 minutes, then $70 \%$ ethanol for $1 \mathrm{~min}$, before rinsing in three changes of sterile distilled water. Excess water was removed by blotting with sterile filter paper. The plant pieces were then placed on the PDA. The Petri dishes were 
incubated at room temperature and observed daily for mycelium growth. Isolated colonies were sub cultured into fresh medium to obtain pure cultures.

The identification of isolated fungi was done according to the method of [14]. A drop of lactophenol cotton blue stain was placed on a clean slide and with the aid of a mounted needle; a small portion of the mycelium from the fungal cultures was removed and placed in the drop of stain. The mycelium was spread on the slide and a cover slip was gently lowered on it. The slide was then examined under the microscope (Olympus model). Morphological characteristics of the fungi such as presence/absence of septum in hyphae, and occurrence of spores were noted. These features, with the aid of identification manuals $[15,16]$, were used in the identification of the isolates to the genus.

\section{RESULTS}

\subsection{Survey}

\subsubsection{Symptoms associated with fungal activity observed in the farms}

Fungal disease symptoms were seen in all fields that were surveyed. Fungal leaf spots were the main symptom observed. The fungal leaf spots were of various sizes and shapes (Plate 1).

\subsubsection{Sugarcane cultivars observed}

During the field survey, we observed that two cultivars of sugarcane (BM and BUF) were grown in Buea area (Plate 2).

Both Cultivars BM and BUF are local cultivars. Cultivar BM was the common type grown in this area, and was seen in all the five villages that were evaluated during the survey; but BUF was observed only in Upper farms. Table 2 gives a comparative description of both cultivars.

\subsubsection{Sugarcane cropping patterns}

We observed during the survey that $65 \%$ of the farms had no weeds, since weeding was done regularly, while the remaining $35 \%$ were poorly managed with lots of weeds noted. Well managed farms were not only weed free but were properly de-trashed.

The farming system observed was mainly mixed cropping. The sugarcane was intercropped with plantains, cassava and cocoyams. These crops were sparsely distributed within these sugarcane farms.

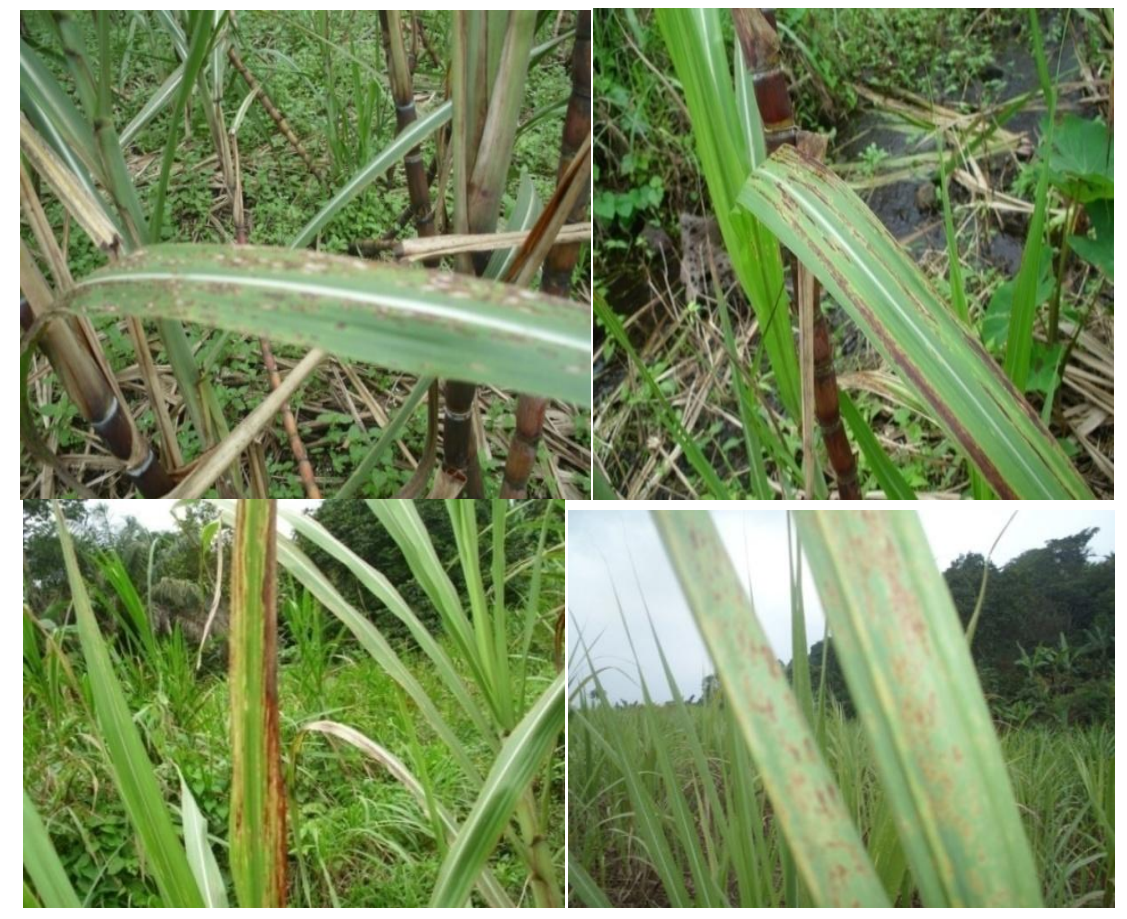

Plate 1. Some symptoms observed on sugarcane leaves associated with fungal activity 


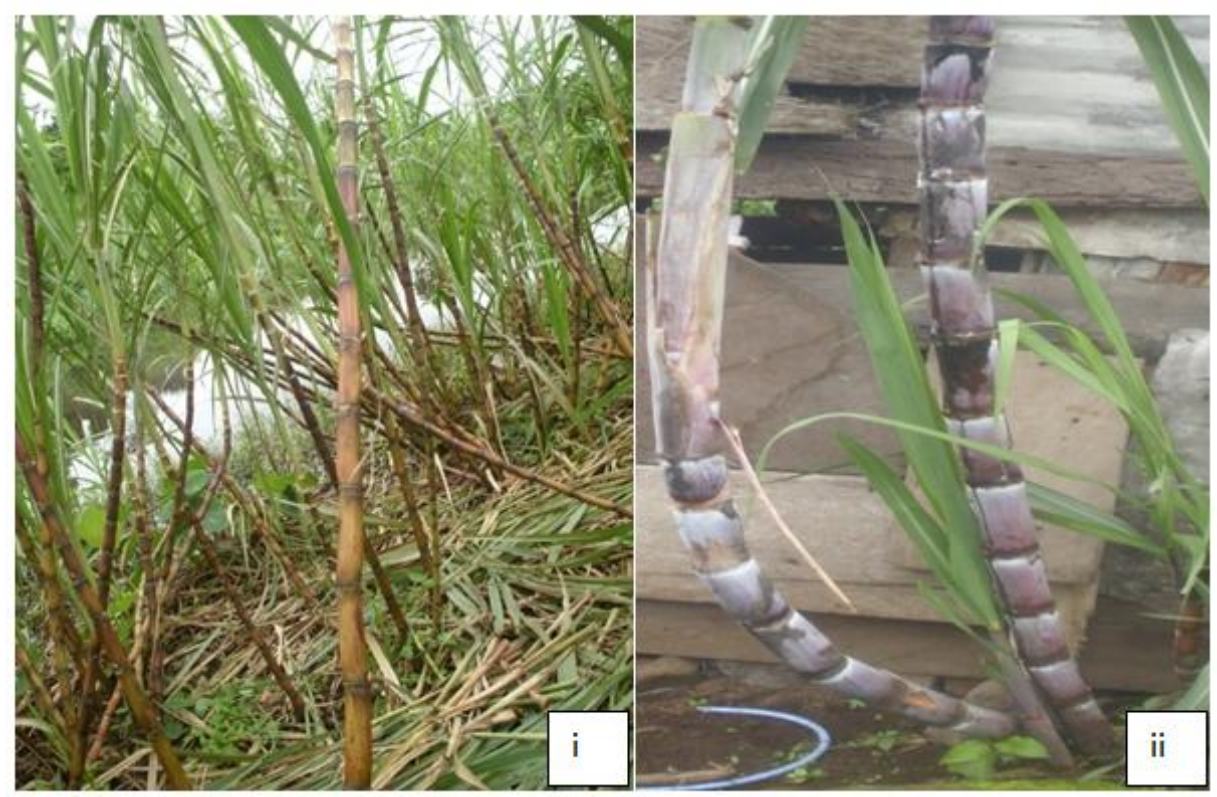

Plate 2. Sugarcane varieties cultivated in Buea area (i) Cultivar BM (ii) Cultivar BUF

Table 2. Brief description of cultivars BM and BUF

\begin{tabular}{lll}
\hline Diagnostic features & Cultivar BM & Cultivar BUF \\
\hline Canopy (leaf angle) & Drooping & Drooping \\
Leaf blade shape & Curved mid & Curved at the top \\
Leaf sheath adherence & Easily shed (self-stripping) & Clings very tightly \\
Leaf sheath wax & None & Present \\
Leaf sheath hair & Present & Present \\
Leaf sheath colour & Green with purplish tint & Purple \\
Bud shape & Pointed & Round \\
Shape of internode & Cylindrical & Bobbin shaped \\
Wax ring & Distinct & Not distinct \\
Growth cracks on internode & Long shallow cracks & Not present \\
Rind & Soft & Very hard \\
\hline
\end{tabular}

\subsubsection{Incidence and severity of fungal disease} symptoms

A total of 23 farms were evaluated for incidence and severity of fungal disease symptoms. The highest incidence (100\%) was recorded in farms in Maumu, Lysoka, Wolikawo and Moli villages. The lowest incidence (54\%) was recorded in Upper farms (Table 3). The highest severity was recorded in Wolikawo village $(55 \%)$ and the lowest severity (20\%) was recorded in Moli village as seen in Table 3.

\subsubsection{Prevalence of fungal symptoms}

Five farms were observed in each village, giving a total of 25 farms observed for disease prevalence. Fungal disease symptoms were identified in all the 25 farms, thus a prevalence of $100 \%$.

\subsection{Information from Questionnaires}

All the 25 questionnaires administered were completed, giving a success rate of $100 \%$. Based on the response from the questionnaires, $86 \%$ of the sugarcane farmers were male and $14 \%$ were female. It also revealed that the main sugarcane farmers in the Buea were men of ages 35 and above. These men grew sugarcane mainly for commercial purposes. These commercial sugarcane farmers grew sugarcane mainly in Maumu, Moli and Lysoka villages and their farms sizes were above 0.5 hectares. 
Table 3. Incidence and severity of fungal disease symptoms in sugarcane in Buea and its environ

\begin{tabular}{lll}
\hline Site & Incidence & Severity \\
\hline $\begin{array}{l}\text { Wolikawo } \\
\text { Village }\end{array}$ & & \\
\hline Farm 1 & $100 \%$ & $39 \%$ \\
Farm 2 & $100 \%$ & $29 \%$ \\
Farm 3 & $100 \%$ & $53 \%$ \\
Farm 4 & $100 \%$ & $55 \%$ \\
Farm 5 & $100 \%$ & $34 \%$ \\
\hline Upper Farms & & \\
\hline Farm 1 & $54 \%$ & $34 \%$ \\
Farm 2 & $60 \%$ & $29 \%$ \\
Farm 3 & $59 \%$ & $27 \%$ \\
\hline Moli Village & & \\
\hline Farm 1 & $100 \%$ & $28 \%$ \\
Farm 2 & $100 \%$ & $29 \%$ \\
Farm 3 & $100 \%$ & $20 \%$ \\
Farm 4 & $100 \%$ & $29 \%$ \\
Farm 5 & $100 \%$ & $33 \%$ \\
\hline Maumu & & \\
Village & & \\
\hline Farm 1 & $100 \%$ & $26 \%$ \\
Farm 2 & $100 \%$ & $40 \%$ \\
Farm 3 & $100 \%$ & $28 \%$ \\
Farm 4 & $100 \%$ & $34 \%$ \\
Farm 5 & $100 \%$ & $29 \%$ \\
\hline Lysoka & & \\
Village & & $29 \%$ \\
\hline Farm 1 & $100 \%$ & $27 \%$ \\
Farm 2 & $100 \%$ & $32 \%$ \\
Farm 3 & $100 \%$ & $39 \%$ \\
Farm 4 & $100 \%$ & $34 \%$ \\
Farm 5 & $100 \%$ & \\
\hline & & \\
\hline
\end{tabular}

Female farmers were found in Upper Farms and Wolikawo villages. These women had home gardens and they grew sugarcane mainly for household consumption. As concerns the educational level of the respondents, $55 \%$ of them had the First School Leaving Certificate as their highest qualification, $10 \%$ were drop outs from secondary schools and $35 \%$ had not had any formal education.

Cultivar BM was the main cultivar grown in Buea and was grown for commercial purposes, while Cultivar BUF was grown mainly for household consumption. The major use of sugarcane in this area is for chewing, especially during the dry season when temperatures are high.

The respondents acknowledged the existence of leaf spots on the sugarcane leaves especially during the rainy season, but did not know these were symptoms of fungal infections. Respondents were not knowledgeable on fungal infection on sugarcane thus; they took no measure to control same. Pesticides were not used in sugarcane cultivation in these areas.

The main cultural practices were weeding and de-trashing. Those who owned large farms use herbicides mainly systemic herbicides (Round up and Herbistar). Information gotten revealed that a large bundle of about 20-25 sugarcane stems cost 3000-3500 FRS. The main buyers of these sugarcanes come from Douala, Limbe, Kumba and even from Buea.

The commercial sugarcane farmers were organized into an association to carter for their social concerns. Within this association, they carried out financial savings weekly and monthly.

\subsection{Isolation and Identification of Fungi}

A total of eight isolates were obtained from the leaf particles plated on PDA. Their texture ranged from velvety to floccose. Their margins were mostly entire and filamentous. The cultural and micro-morphological characters of some representative isolates are shown in Plates 3-5. Majority $(80 \%)$ of the fungi identified were Bipolaris sp., $15 \%$ were Chaetomium sp. and $5 \%$ was a septate sterile fungus (Mycelia sterilia). Bipolaris sp. and Chaetomium sp. were isolated in all the villages, while the Mycelia sterilia was isolated only in Wolikawo and Maumu villages (Table 4). The Bipolaris sp showed variation in their cultural and colony characteristics.

The texture of the Mycelia sterilia was velvety, the margin was entire, the elevation umbonate, the shape circular and the surface colour was greyish brown and the reverse side colour was black (Plate $5 \mathrm{i}$ and ii). The sterile septate fungi did not sporulate in PDA. These sterile septate fungi were re-cultured in corn meal agar which is a nutritionally deficient agar to induce sporulation but it still did not sporulate.

\section{DISCUSSION}

The survey reported here has shown that there is a high incidence of fungal diseases in sugar canes in the study area. The diverse cropping system in the fields surveyed may also be facilitating the survival and propagation of these pathogens since fungi are able to survive in alternate hosts. 


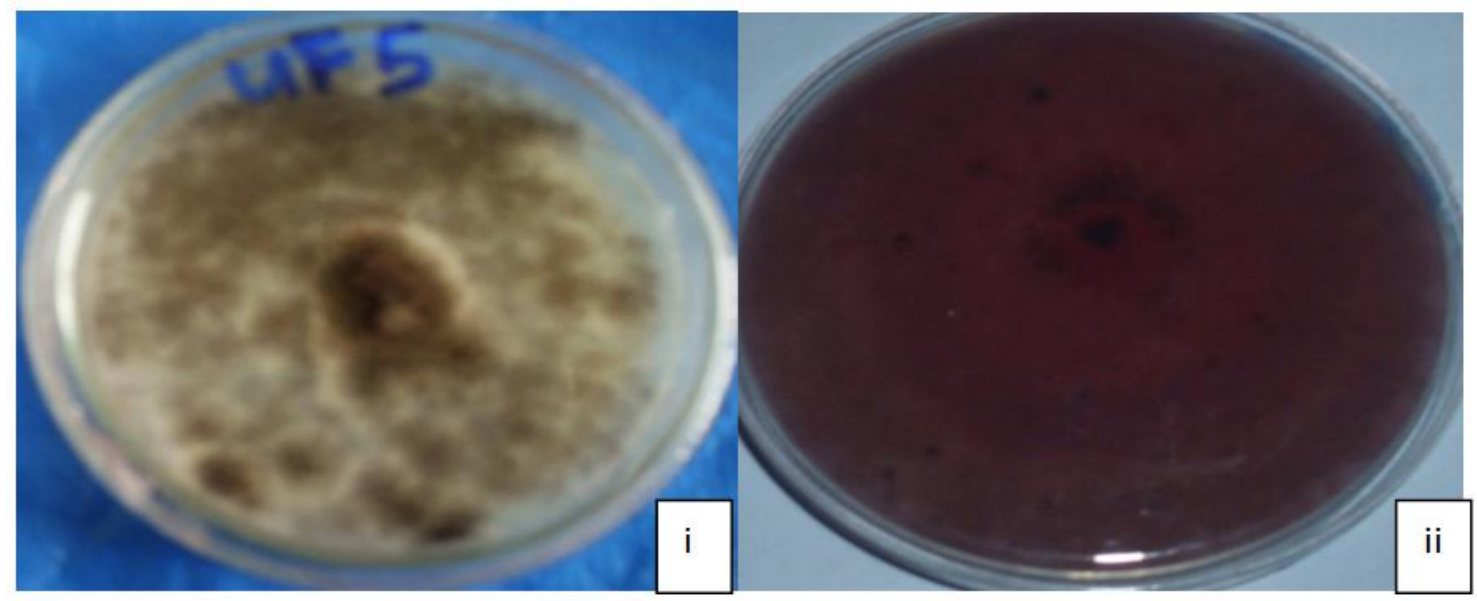

Plate 3a. Culture of Chaetomium isolate on potato dextrose agar (i) Front view (ii) Reverse view

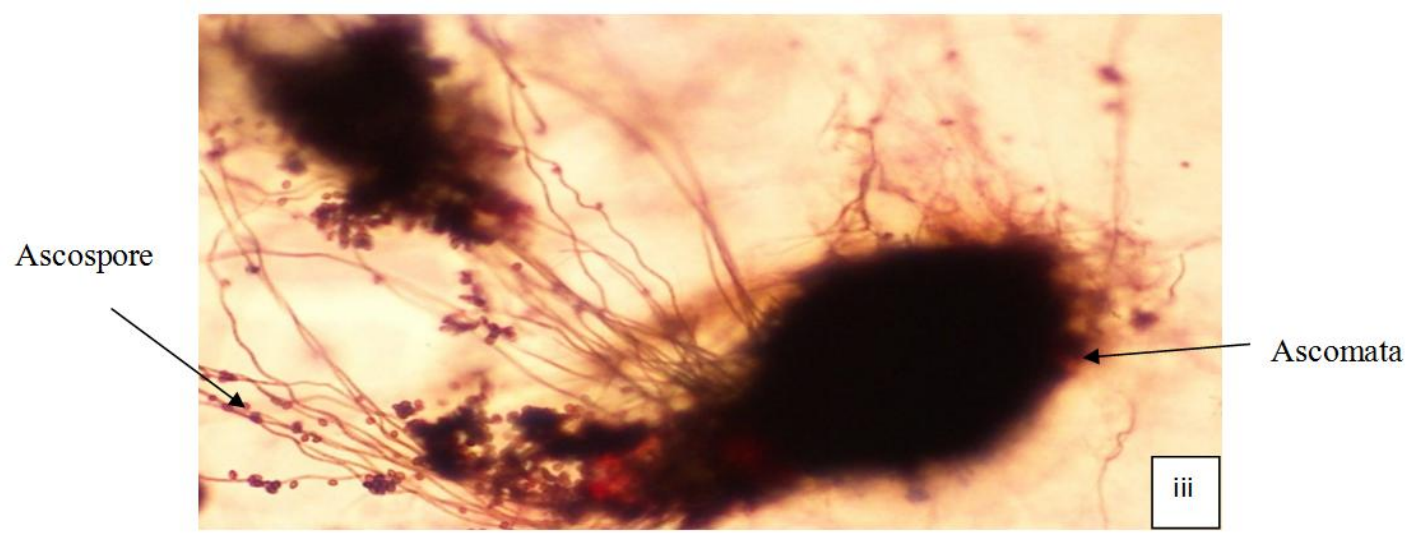

Plate 3b. Micro-morphological presentation of Chaetomium sp
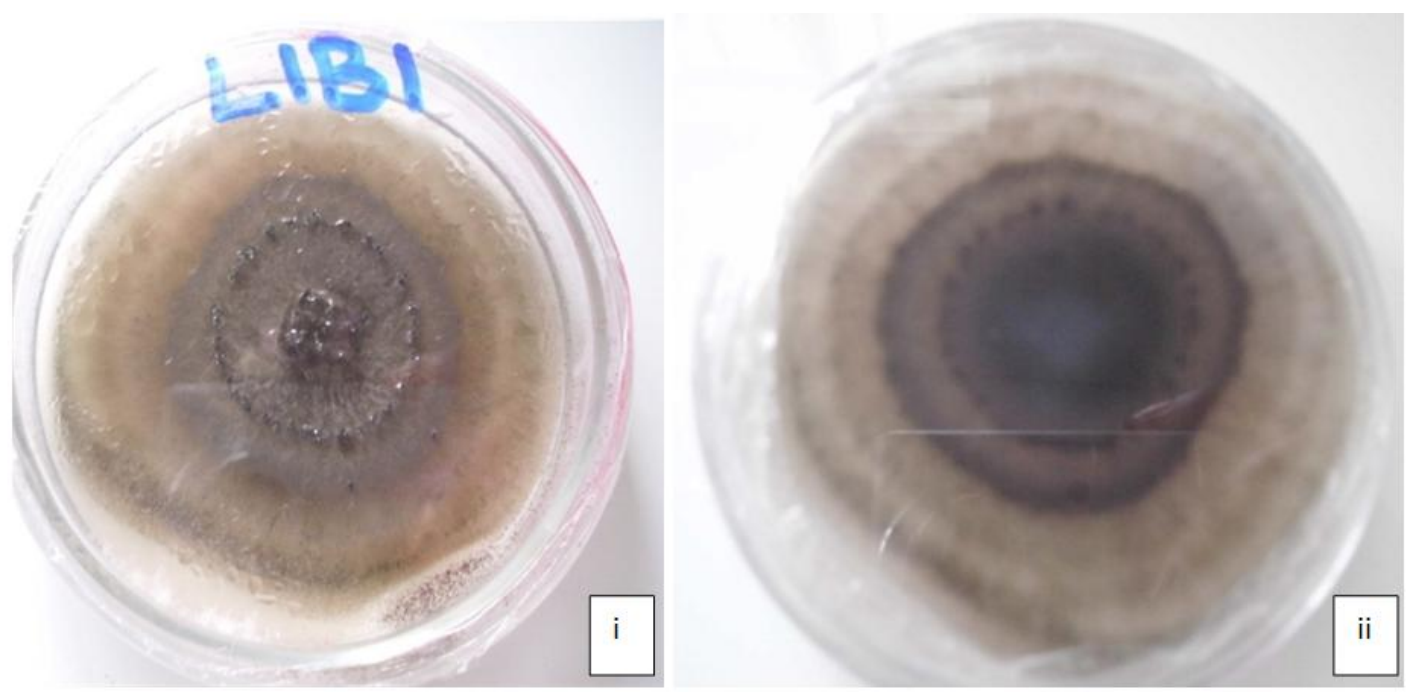

Plate 4a. Culture of Bipolaris isolate on potato dextrose agar (i) Front view (ii) Reverse view 


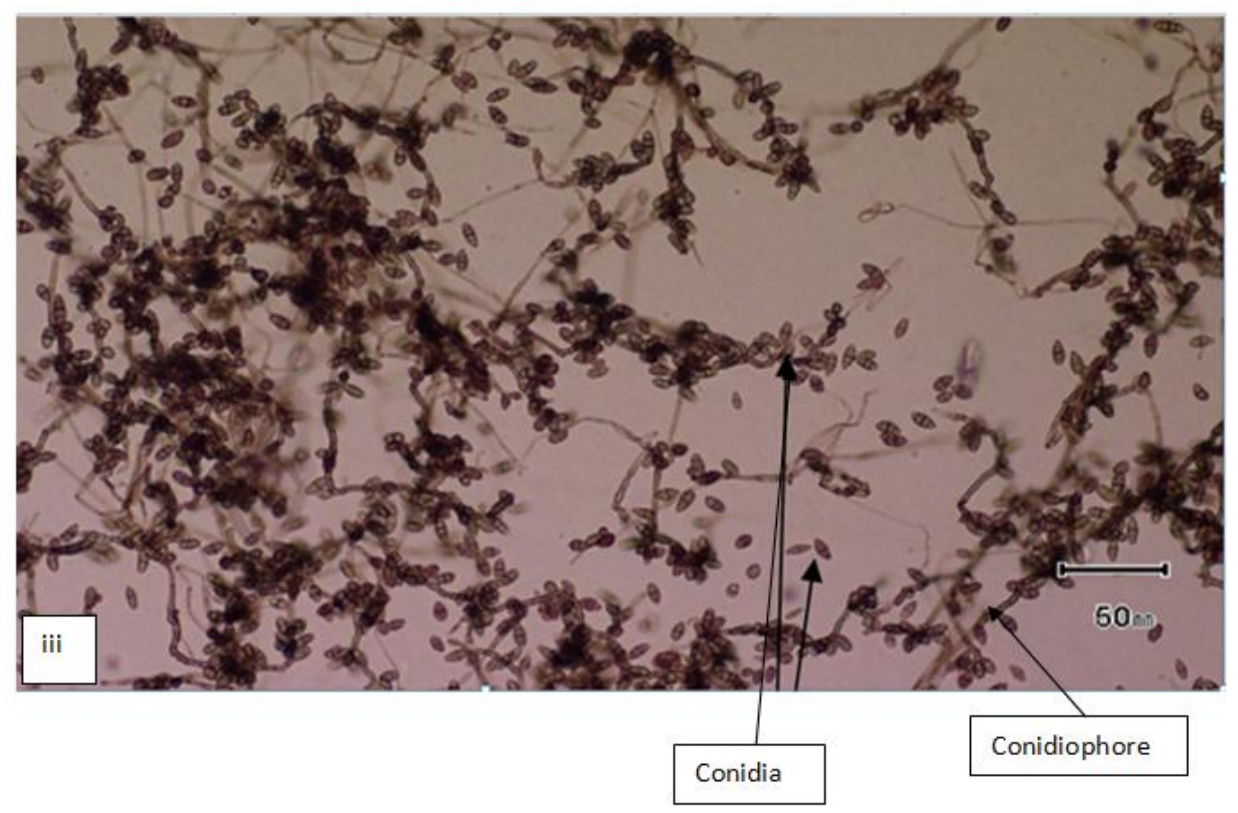

Plate 4b. Micro-morphological presentation of Bipolaris sp
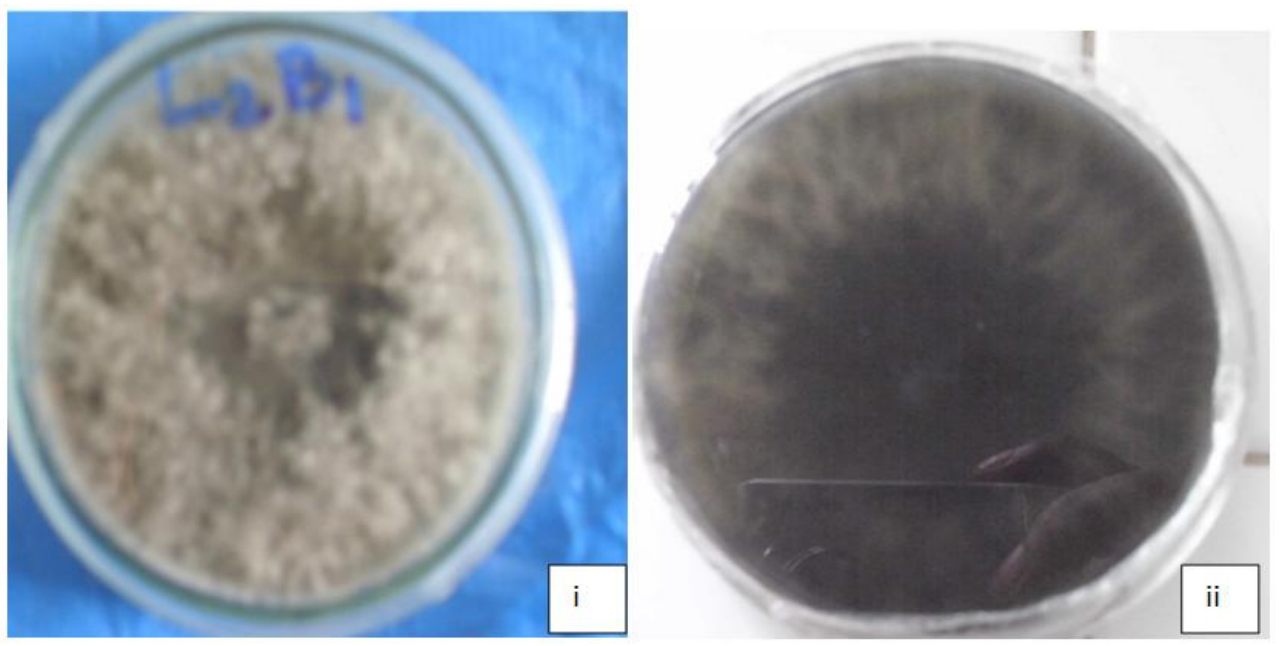

\section{Plate 5a. Culture of Mycelia sterilia isolate on potato dextrose agar (i) Front view (ii) Reverse view}

Despite the presence of fungal disease symptoms in all the farms surveyed, the severity was averagely low (approximately 30\%) except in farms that had been abandoned due to land use changes, like in Moli, Lysoka and Maumu villages. The farmlands in these villages had been given out as plots for constructions.

The fungal symptoms were more visible in the month of July, August and September. These months were the peak of the rainy season in this region. The variation in disease severity may indicate the existence of isolates differing in pathogenicity. The risk of cultivating sugarcane is low because despite the presence of fungal pathogens the severity is relatively low when the farms are properly managed.

During the survey it was realized that the sugarcane landrace BUF was less susceptible to fungal pathogens because they did not show any fungal symptoms. The BUF landrace was found only in Upper Farms that was why the incidence was less than $100 \%$ in this location; meanwhile the landrace BM was more susceptible 


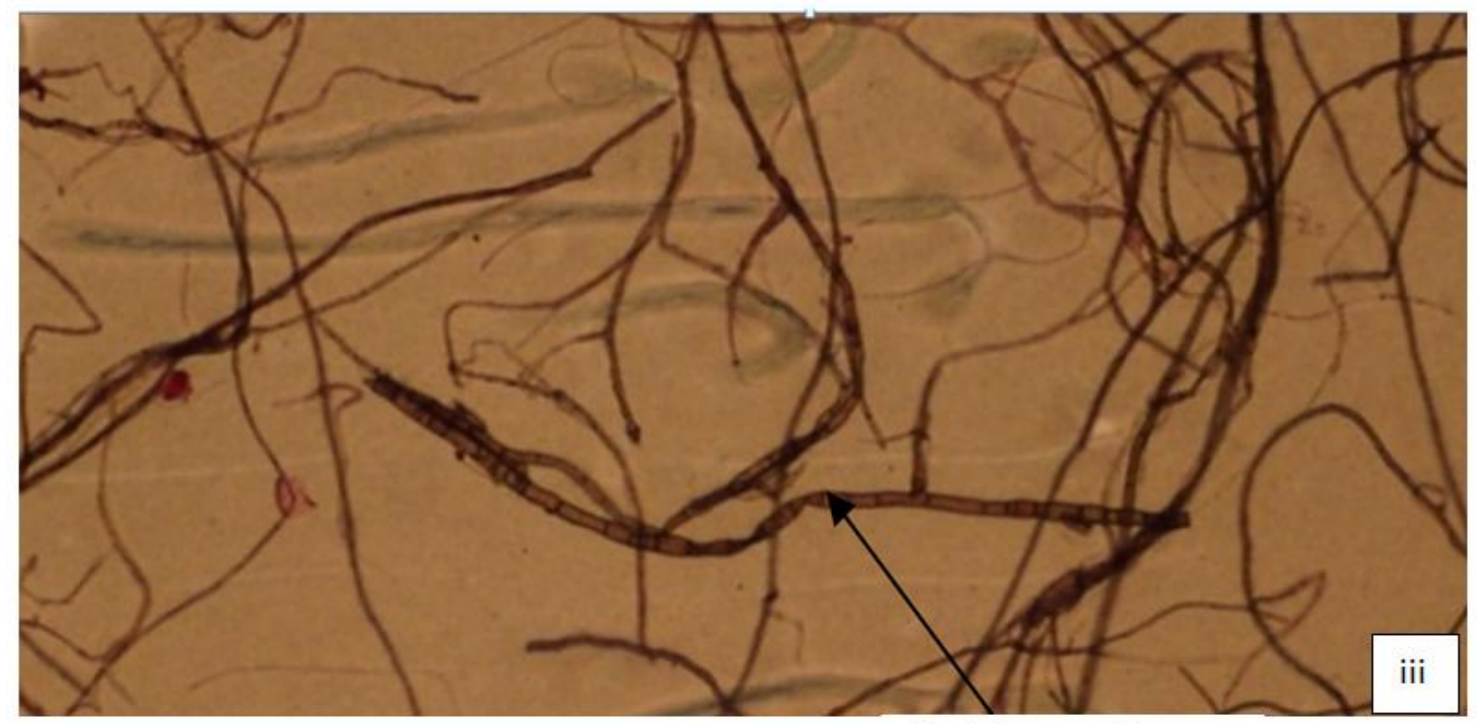

Septate mycelium

Plate 5b. Micro-morphological presentation of the septate Mycelia sterilia

Table 4. Fungi isolates identified in the different study sites

\begin{tabular}{ll}
\hline Location & $\begin{array}{l}\text { Fungal isolates } \\
\text { identified }\end{array}$ \\
\hline Wolikawo & $\begin{array}{l}\text { Bipolaris sp } \\
\text { Chaetomium } \mathrm{sp} \\
\text { Mycelia sterilia }\end{array}$ \\
\hline Upper farms & $\begin{array}{l}\text { Bipolaris } \mathrm{sp} \\
\text { Chaetomium } \mathrm{sp}\end{array}$ \\
\hline Moli village & $\begin{array}{l}\text { Bipolaris } \mathrm{sp} \\
\text { Chaetomium } \mathrm{sp}\end{array}$ \\
\hline Maumu village & $\begin{array}{l}\text { Bipolaris sp } \\
\text { Chaetomium } \mathrm{sp} \\
\text { Mycelia sterilia }\end{array}$ \\
\hline Lysoka village & $\begin{array}{l}\text { Bipolaris } \mathrm{sp} \\
\text { Chaetomium } \mathrm{sp}\end{array}$ \\
\hline
\end{tabular}

to fungal diseases because they exhibited fungal symptoms and this landrace was more common in Buea and its environ. Most sugarcane farmers preferred to cultivate landrace BM for commercial purposes because it was softer and easier to chew, a reason why consumers preferred it to BUF.

Majority of the respondents had no formal education and only few of them had attained primary and secondary education. Knowledge on the management of a disease is very important in the incidence and control of that particular disease, thus the low educational level of most of the farmers could be a disadvantage in adopting improved agronomic practices such as roguing of diseased plants, destruction of crop residues and the elimination of living plants that carry pathogens. Again due to ignorance farmers may undertake certain practices that may result in the spread of diseases.

Most farmers lacked knowledge on disease identification and they indicated that they do not use any strategies to control diseases. The sugarcane farmers in this area do not use fertilizers and they do not irrigate as well.

Of all the fungi isolated, $80 \%$ belonged to Bipolaris sp. and $15 \%$ Chaetomium sp. This finding was similar to the results of [17] in which six Chaetomium species and four Bipolaris species were associated with the mycobiota of four sugarcane landraces in Iraq. However this is the first report of the occurrence of these species in the mycobiota of sugarcane in Buea and its environs.

Bipolaris sacchari is known as the causative agent of Eye spot disease of sugarcane and Bipolaris stenospila is also known as the causative agent of Brown stripe disease of sugarcane $[18,19]$. This indicated that Bipolaris is 
a pathogenic fungus that is associated with diseased sugarcane.

The variation in morphological and cultural characteristics in the Bipolaris isolates also indicated the likelihood that there are more than one species of Bipolaris associated with sugarcanes in Buea area.

Reference [8] published the first report of orange rust in sugarcane caused by Puccinia kuehnii in Cameroon. This study was carried out in the SOSUCAM sugarcane plantations in Mbandjock and Nkoteng.

\section{CONCLUSION}

Sugarcane fungal symptoms are present in Buea and its surrounding environments. Despite the presence of fungal disease symptoms in the various locations, the management practices of the farmers played a major role in determining the severity. Management of fungal pathogens on sugarcane required that farmers exercise good farm practices. Bipolaris species were the main pathogens isolated from diseased sugarcane in this study area, thus management strategies must target this fungus which has a worldwide distribution and a broad host range.

\section{ACKNOWLEDGEMENT}

We would like to thank all the sugarcane farmers who gave us access to their farms, the staffs of the Rubber Pathology Laboratory, IRAD Ekona and those of the Life Sciences Laboratory of the University of Buea for their assistance. We also appreciate the comments from the anonymous reviewers which have helped in improving the quality of the manuscript.

\section{COMPETING INTERESTS}

Authors have declared that no competing interests exist.

\section{REFERENCES}

1. Raid RN, Comstock JC. Sugarcane rust disease. Agronomy Department Document SS-AGR-207. University of Florida/IFAS, Gainesville, FL32611; 2006.

2. Singh RK, Kumar P, Tiwari NN, Rastogi J, Singh SP. Current status of sugarcane transgenic: An overview. Advancement in Genetic Engineering. 2013;2:112.
3. Cheavegatti - Gianoto $A$, de Abreu, $H$, Arruda P, Bespalhok Filho J. Bumquits. W, Creste. S, di Ciero L, Ferro J, Oliveira Fiqueira A, de Sousa Filgueiras T, Grossi de - sa M, Guzzo. E, HoffmanH, Andrade Landell M, Macedo N, Matsuoka S, Castro Reinach. F, Romano. E, da Silva. W, de Castro Silva Filho. M, Cesar Ulion. E. Sugarcane (Saccharum X officinarum): A Reference study for the Regulation of Genetically modified landraces in Brazil. Tropical Plant Biology. 2011;1-28.

4. Ahmed I, Shah Alam M, Rafiul I, Shahidul Alaim, Tae -Soo Lee. In vitro studies on Collectotrichum falcatum the causal agent of red rot disease of sugarcane. American -Eurasian. Journal of Agric. \& Environ Sci. 2007;2(5):511-517.

5. FAOSTAT. Food and Agriculture Organization Corporate Statistical Database; 2013.

6. Business in Cameroon (2013).

7. Matsuoka S, Maccheroni W. Chapter 6: Disease management. In: Santos CA, Borém C, Caldas C, editors. Sugarcane: agricultural production, bioenergy, and ethanol. Academic Press; San Diego, CA, USA. 2015;115-132. [CrossRef] [Ref list]

8. Saumtally AS, Viremouneix TR, Ahondokpe B, Girard JCR, Castlebury LA, Dixon L, Glyn NC, Comstock JC. First report of orange rust of sugarcane caused by Puccinia kuehnii in Ivory Coast and Cameroon. American Phytopathological Society. 2011;95(3):357.

9. Egbe EA, Tabot PT. Carbon Sequestration in eight woody non timber species and their economic potentials in the South Western Cameroon. Applied Ecology Env'tal Resource. 2011;9:369-385.

10. van Barneveld GW. Agroclimatic conditions of West Africa and Cameroon, in Proceedings of the 3rd International Forum on Soil Taxonomy and AgroTechnology Transfer, H. Ikawa and G. Y. Tsuji, Eds., Benchmark Soils Project Technical Report. 1987;10:121-133. University of Hawaii.

11. Agrios GN. Plant pathology. Elsevier Academic Press, London; 2005.

12. Patil SB, Bodhe SK. Leaf disease severity measurement using image processing. Int. J. Eng. Technol. 2011;3:297-301.

13. Bechem ET, Afanga YA. Morphological and molecular identification of fungi associated with corm rot and blight symptoms on plantain (Musa paradisiaca) 
in macro-propagators. Int. J. Biol. Chem. Sci. 2017;11(6):2793-2808.

14. Fawole MO, Oso BA. Laboratory manual of microbiology. Spectrum Books Limited Ibadan. 1995; 14-56.

15. Watanabe T. Pictorial atlas of soil and seed fungi: Morphologies of cultured fungi and key to species $\left(2^{\text {nd }}\right.$ edn $)$. CRC Press LLC; 2002.

16. Barnett HL, Hunter BB. Illustrated genera of imperfect fungi. The American Phytopathological Society. St. Paul, Minnesota (USA): Aps Pres; 1999.
17. Abdullah SK, Salih YA. Mycobiota associated with sugar cane Saccharum officinarum landraces in Iraq . 1. Mitosporic fungi. J. Duhok Univ. 2010;13(1):130-138.

18. Ricaud C, Egan BT, Gillaspie AG. Jr, Hughes CG. Diseases of sugarcane: Major diseases. Elsevier Publ. Amsterdam; 1989.

19. Rott P, Bailey RA, Comstock JC, Croft BJ, Saumtally AS (eds). A guide to sugarcane diseases. CIRAD Publication Service, Montpellier, France. 2000;340.

(c) 2019 Bechem and Mbella; This is an Open Access article distributed under the terms of the Creative Commons Attribution License (http://creativecommons.org/licenses/by/4.0), which permits unrestricted use, distribution, and reproduction in any medium, provided the original work is properly cited.

\section{Peer-review history:}

The peer review history for this paper can be accessed here: http://www.sdiarticle3.com/review-history/47825 